\title{
GESTIÓN DE LA CALIDAD: UNA PRÁCTICA GERENCIAL PARA IMPULSAR EL CAMBIO CONTABLE EN PYMES DE REDES COMERCIALES AUTOMOTRICES DE ARGENTINA
}

\author{
Fabiana Andrea Casarsa \\ Universidad Nacional del Sur \\ Argentina \\ ORCID: 0000-0003-1386-744X \\ E-mail: fcasarsa@uns.edu.ar \\ Liliana Marcela Scoponi \\ Universidad Nacional del Sur \\ Argentina \\ ORCID: 0000-0003-2179-2150 \\ E-mail: liliana.scoponi@uns.edu.ar
}

Recebido em: 02/06/2020

Aprovado em: 08/09/2020

\section{RESUMEN}

En un contexto dinámico y altamente competitivo, las terminales automotrices buscan la fidelización de los clientes, convirtiendo a la calidad en un factor crítico de éxito que debe gerenciarse e incorporarse en la planificación y administración estratégica de costos. Ello ha promovido en los últimos años, la renovación de prácticas gerenciales vinculadas a la gestión de la calidad en las pequeñas y medianas empresas (PyMEs) que integran la red comercial de concesionarias de su marca. Atendiendo las dificultades en los procesos de interiorización e institucionalización de nuevas rutinas de la Contabilidad de Gestión (CG) en las PyMEs, el presente trabajo tiene como objetivo presentar un reporte de costos e indicadores de calidad integrado al sistema de información de la CG diseñado para el Departamento de Servicio, de modo de analizar los principales factores que pueden influir en el proceso de cambio, e identificar impulsores y barreras sobre los cuales accionar. El estudio empleó una metodología cualitativa basada en casos múltiples, sobre cuatro concesionarias argentinas, a partir de análisis documental, entrevistas y observación directa. A los fines de entender la dinámica del cambio contable, se aplicó el modelo de Cobb et al. (1995), reordenado a su vez a partir del modelo de Bogt \& Helden (2000), para identificar y categorizar los factores que afectan el cambio contable en las empresas analizadas. Se encontraron patrones similares de control gerencial en las terminales automotrices para la administración de su red comercial a los fines de un mejor alineamiento con su estrategia y modelos de gestión.

Palabras clave: Costos de la calidad. Indicadores de desempeño. Contabilidad gerencial. Cambio. PyME.

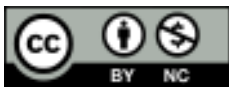




\section{INTRODUCCION}

Actualmente, los clientes demandan productos y servicios de calidad superior, en virtud de lo cual, las empresas han tenido que incorporar este concepto como una dimensión competitiva clave en la toma de decisiones estratégicas (Shank \& Govindarajan, 1995; Ksairi, 2006; Hansen \& Mowen, 2007). En función de esta filosofía, se observa mayor énfasis en los procesos de gestión que tienen como objetivo diseñar, planear y controlar las condiciones que afectan lo que el cliente piensa y siente. Frente a este contexto, las terminales automotrices están promoviendo la renovación de prácticas gerenciales vinculadas a la gestión de la calidad en las pequeñas y medianas empresas (PyMEs) que integran la red comercial de concesionarias de su marca. En un contexto dinámico y altamente competitivo, buscan la fidelización de los clientes, convirtiendo a la calidad en un factor crítico de éxito que debe gerenciarse e incorporarse en la planificación y la administración de costos.

La determinación de costos e indicadores de la calidad a través de un reporte integrado al sistema de información de la Contabilidad de Gestión (CG) se torna así esencial, si una organización decide prestar atención al mejoramiento y control de este tipo de costos y de las actividades que los generan (Hansen \& Mowen, 2007). Una de estas actividades en las concesionarias automotrices, es el servicio de postventa, que las terminales valorizan para la medición de desempeño de su red comercial, dado que constituye una fuente de retroalimentación de la información relativa a la situación competitiva de la cadena de valor interna y externa para lograr lealtad de los clientes.

Sin embargo, los procesos de interiorización e institucionalización de nuevas rutinas de la CG en las PyMEs no son sencillos ni inmediatos (Facin Lavarda, Ripoll Feliú \& Barrachina Palanca, 2009a). Atendiendo estas dificultades, el presente trabajo tiene como objetivo evaluar el grado de adopción de un sistema de información de costos e indicadores de la calidad para el control de gestión diseñado para el Departamento de Servicio, denominado Reporte de Evaluación de Desempeño de la Calidad, de modo de analizar los principales factores que influyen en el proceso de cambio, e identificar impulsores y barreras sobre los cuales accionar. El reporte propuesto aporta información sobre las actividades de calidad o conformidad (prevención y evaluación) y de no calidad o no conformidad (fallas internas y fallas externas), cuantificando los costos respectivos y brindando un conjunto de indicadores financieros y no financieros con el propósito de apoyar a los directores y gerentes en la planeación, el control y la toma de decisiones de mejora continua.

Los estudios de procesos de cambio en la Contabilidad de Gestión se han incrementado en los últimos años en la búsqueda de identificar las diferencias entre la teoría y la práctica en la realidad organizacional (Guerreiro, Agurto Berdejo, Pereira \& Beuren, 2012). Por otro lado, numerosas evidencias empíricas sobre el incumplimiento de predicciones teóricas planteadas para la gran empresa, justifican un campo de investigación en CG centrado en las PyMEs con identidad propia (Facin Lavarda, Barrachina Palanca \& Ripoll Feliú, 2010).

El presente trabajo se estructura de la siguiente manera: en la sección 2, se desarrolla el marco teórico que fundamenta el estudio, identificando la información de costos necesaria para apoyar una adecuada gestión de la calidad y analizando diferentes enfoques orientados a interpretar el cambio en la CG derivado de nuevos reportes; en la sección 3, se exponen los aspectos metodológicos de la investigación; en la sección 4, se plantean los resultados obtenidos en las empresas analizadas; y, finalmente en la sección 5, se presentan las conclusiones. 


\section{MARCO TEORICO DE REFERENCIA}

\subsection{La Gestión de la Calidad como factor clave en la administración de costos}

Frente a la creciente exigencia de los clientes por productos y servicios de calidad superior, las empresas han tenido que incorporar este concepto en la toma de decisiones estratégicas (Shank \& Govindarajan, 1995; Ksairi, 2006; Hansen \& Mowen, 2007). Para mejorar la calidad deben realizarse inversiones en las distintas actividades que las empresas desarrollan. Si bien el concepto de calidad se aplica en varios ámbitos, en una empresa se refiere a los requisitos que deben cumplir los bienes y servicios que se ofertan para estar aptos para su comercialización. Estos surgen de las exigencias o necesidades que se establecen desde el punto de vista interno o externo de un ente, fijando un marco de eficiencia operativo satisfactorio en las distintas actividades que integran la cadena de valor (Ksari, 2006). En lo que respecta al funcionamiento interno de la organización, se refiere a las especificaciones, normas y procedimientos formulados para lograr resultados satisfactorios en la obtención de los productos o prestación de los servicios. Por su parte, los requisitos externos están vinculados con las expectativas o exigencias de los compradores (consumidor final o intermedio), pero también con las condiciones que impone el mercado competidor.

La Sociedad Estadounidense para el Control de Calidad (American Society for Quality Control) define la calidad como el total de rasgos y características de un producto o servicio, fabricado o realizado según las especificaciones para la satisfacción de los clientes. En general, si las empresas se enfocan en la calidad, sea de un producto o de un servicio, adquirirán experiencia en su producción o prestación, se reducirán de esta manera los costos asociados, se logrará mayor satisfacción de los clientes, y se generarán ingresos futuros más altos. En algunos casos, el beneficio de una mayor calidad se refleja en mantener a los clientes, y por ende, conservar los ingresos, y no en generar ingresos más altos. Una empresa que no invierta en el mejoramiento de la calidad mientras sus competidores lo están haciendo, probablemente sufrirá una disminución en su participación de mercado, ingresos y ganancias (Horngren, Foster \& Datar, 2002).

Los costos de calidad son los costos necesarios para alcanzar la calidad (Hansen \& Mowen, 2007). Es decir, son aquellos en los que se incurre por prevención para evitar mala calidad en los productos o servicios, o bien los costos que surgen como resultado de la producción de baja calidad que no cumple con las especificaciones o necesidades de los clientes (Horngren, Foster \& Datar, 2002; Hansen \& Mowen, 2007). Según Climent Serrano (2005a), los costos de calidad son todos los costos ocasionados para la obtención de un producto o servicio idóneo en calidad a las necesidades del usuario. En este sentido, expresa que deben incluirse todos aquellos costos en los cuales la empresa incurre en actividades de prevención y control para que el producto o servicio sea entregado al cliente en las condiciones óptimas requeridas, así como también los costos ocasionados por defectos o fallas del producto o servicio, sean éstas detectadas por la empresa o bien por el usuario/cliente. Recalcando que no deben olvidarse en esta última situación, los posibles costos intangibles ocasionados por la mala imagen o pérdida de ventas. Los costos de calidad se encuentran en todas los sectores o áreas de la empresa, incluso también influyen en los costos de calidad de otras empresas. Por ejemplo, la calidad de los proveedores puede repercutir hacia adelante en la cadena de valor, es decir, en nuestros clientes. De ahí que las terminales automotrices gestionen su cadena de valor bajo programas de calidad, extendiendo esta filosofía no sólo

Management Control Review, v. 5, n. 2, Jul/Dez, pp. 40-60, 2020. ISSN 2526-1282. 
hacia atrás de la cadena, sino también hacia adelante en sus concesionarias de la red comercial, que deben ampliar su aplicación en su propia cadena de valor. Entonces, para justificar estos sacrificios económicos es necesario no sólo identificar a los costos de calidad, sino también medirlos para tomar conciencia de las implicancias del problema e implementar medidas tendientes a su mejora.

La clasificación de los costos de calidad sirve a los decisores de las organizaciones como herramienta estratégica de información (Climent Serrano, 2005a). A continuación se presentan distintos criterios de clasificación de los costos de calidad que serán de utilidad para el estudio que se realiza.

Clasificación de acuerdo a su posible medición en unidades monetarias, físicas u otras

a) Costos tangibles, explícitos u observables: son los costos que se pueden medir en forma objetiva, ocasionados por la falta de calidad o bien para obtener una calidad específica. Estos costos se encuentran contabilizados, es decir pueden obtenerse de los registros contables y reflejarse en el Estado de Resultados de la empresa (Hansen \& Mowen, 2007). Por ejemplo, el costo de la mano de obra que se incurre en actividades de mejoramiento de la calidad o de fallas, costos de mantenimiento preventivo, costos de capacitación del personal, etc.

b) Costos intangibles u ocultos: son costos que no pueden cuantificarse objetivamente, puesto que no aparecen registrados en la contabilidad. Son costos imputados valorados a través de los costos de oportunidad que resultan de la mala calidad (Hansen \& Mowen, 2007). En esta categoría se incluyen aquellos costos derivados de la imagen de la empresa, de la insatisfacción de los clientes, del grado de involucramiento del personal, etc. Por ejemplo: pérdida de ventas por falta de satisfacción de los clientes, aumento de los costos financieros por saldos excesivos de cuentas a cobrar, el exceso de los niveles de stock, la desmotivación del personal.

Clasificación en función de la adecuación al cliente

Las actividades relacionadas con la calidad son las que realizan las organizaciones debido a que existe o podría existir mala calidad. En este sentido se realizan actividades de control y actividades de fracaso o falla. Las actividades de control son las que tienen como objetivo prevenir o detectar mala calidad, donde se efectúan primero las actividades de prevención y después se implantan actividades de evaluación. Las actividades de control generan costos de control. Por su parte, las actividades de fracaso o falla son ejecutadas por las organizaciones o por sus clientes en respuesta a la mala calidad, generando costos de corrección (Hansen \& Mowen, 2007). En síntesis, cuando las cosas pueden salir mal, se incurre en costos de prevención y evaluación; cuando las cosas salen mal, se experimentan costos de falla.

AECA (1995:73) distingue dos grandes grupos y define cuatro categorías de costos:

a) Costos de calidad: son los que la empresa incurre para prevenir y controlar que el producto o servicio cumpla con las especificaciones de calidad. Son aquellos costos que se originan a consecuencia de las actividades de prevención y de evaluación que la empresa debe realizar en un plan de calidad. Es decir, se trata de costos controlables por la empresa, ya que ella decidirá cuánto se gasta/invierte en prevenir y evaluar para mejorar la calidad. También son llamados costos de conformidad (Ostengo, 2014). A su vez, se pueden clasificar en:

- Costos de prevención: Son los costos en que incurre la empresa para prevenir una calidad deficiente en los productos o servicios que se están elaborando. Son los costos que se consumen en las distintas actividades para asegurar que los productos o los servicios cumplan con los requisitos de calidad deseados desde el principio. A medida que aumentan los costos de prevención, se espera que los costos de las fallas disminuyan (Hansen \& Mowen, 2007). 
Ejemplos de este tipo de costos son: los costos en evaluación y selección de proveedores, el mantenimiento preventivo de equipos y herramientas, revisiones de diseño, las auditorías de calidad, los costos de programas de capacitación de la mano de obra, también incluye los costos generados en las actividades de prevención durante el ciclo de comercialización, y los costos de certificación de los sistemas de calidad.

- Costos de evaluación (o costos de detección): son los costos en que incurre la empresa para garantizar que los productos o servicios no conformes con las normas de calidad sean identificados antes de la entrega al cliente. Por ejemplo: costos de inspección y pruebas de materias primas y de empaques, actividades de evaluación de la supervisión, erogaciones en oportunidad de la aceptación de productos y/o servicios, como así también en las actividades de aceptación de procesos (se refiere al muestreo de artículos/servicios mientras todavía estén en proceso, para determinar si el proceso se encuentra bajo control y se están generando productos o servicios sin defecto, caso contrario hay que tomar medidas correctivas). También se incluyen en esta categoría costos generados en verificación de proveedores, pruebas de campo, y costos de auditorías de los sistemas de certificación de la calidad. El objetivo de la función de evaluación es evitar que productos o servicios no conformes lleguen a los clientes (Hansen \& Mowen, 2007).

b) Costos de no calidad: AECA define los costos de no calidad o de fallas como los costos ocasionados por la falta de calidad de los productos o servicios. También son denominados costos de no conformidad (Ostengo, 2014). Estos costos no son controlables directamente por la empresa, ya que se originan en errores o fallas en los productos o bien en la prestación de los servicios. En esta categoría se incluyen, además, los costos de oportunidad o costos intangibles. Estos costos a su vez se clasifican en:

- Costos de fallas internas: son los costos que se generan en la empresa para rectificar todas las fallas o errores que se descubren mientras el producto aún está en la empresa, o bien el servicio no está totalmente prestado. Se presentan cuando se detectan productos y servicios no conformados antes de que lleguen a los clientes. Son fallas percibidas o detectadas por las actividades de evaluación y pueden ser muy costosas. Por ejemplo: desperdicios, tiempo perdido para corregir defectos, re inspección, reprocesos o trabajos repetidos y sus correspondientes insumos y mano de obra, pruebas posteriores y cambios de diseño. Estos costos desaparecen si no hay defectos.

- Costos de fallas externas: son aquellos en los que se incurre porque los productos y los servicios no están de conformidad con las especificaciones o necesidades de los clientes, luego que les son entregados. Estos son los costos de calidad más devastadores para la organización, dado el efecto multiplicador que cualquier falla externa tiene, principalmente por deterioro de la imagen de la empresa y de lo que comercializa (Hansen \& Mowen, 2007). Pueden incluir: devoluciones por mala calidad, ventas perdidas por el mal desempeño del producto, devoluciones y bonificaciones por pobre calidad, garantías, reparaciones, responsabilidad del producto, insatisfacción del cliente, pérdida de participación en el mercado, solución de quejas, costos de las reclamaciones, indemnizaciones, etc. Estos costos desaparecen cuando no existen defectos.

Clasificación en función de los sectores o actividades de la organización

Esta clasificación podría incorporarse dado que es útil a los efectos de obtener información sobre los sectores o actividades en que se originan los costos (Climent Serrano, 2005a, 2005b). Por ejemplo: de producción, de ventas, de post-venta, de compras, facilitando la evaluación del desempeño por áreas de responsabilidad.

La calidad es una variable estratégica indudablemente importante que la contabilidad gerencial no puede desconocer (Shank \& Govindarajan, 1995). Los informes o reportes de la 
contabilidad de gestión constituyen una de las formas importantes a través de las cuales la estrategia se comunica a toda la organización, ofreciendo una retroalimentación específica y oportuna a partir de medidas o indicadores de desempeño financieros y no financieros (Martínez Ramos, 2004, 2005). Por lo tanto, la necesidad de mejorar las prácticas gerenciales orientadas a la calidad, impulsa paulatinamente el cambio contable en las PyMEs concesionarias de marcas automotrices para satisfacer el posicionamiento competitivo que pretenden sus terminales. En este sentido, la utilización rutinaria de reportes sobre costos de calidad puede mejorar la planeación, el control y la toma de decisiones en contextos dinámicos y contribuir al alineamiento estratégico (Facin Lavarda, Ripoll Feliú \& Barrachina Palanca, 2010).

\subsection{La dinámica del cambio contable}

Las necesidades de información en las organizaciones se van modificando para poder atender los cambios en el entorno y en las estructuras organizacionales, viéndose alterada su naturaleza y cantidad requerida para poder llevar a cabo una gestión efectiva. En consecuencia, también debe cambiar el modo en que se utiliza la información para medir y motivar el rendimiento, o para la toma de decisiones. Es así, que el sistema de CG y control de gestión tiene un papel destacado en dos aspectos. En primer lugar, la gerencia puede emplear ese potencial informativo para introducir cambios en prácticas gerenciales que permitan ajustar la organización a la nueva situación interna o externa. En segundo término, el propio sistema de CG y control de gestión puede cambiar para adaptarse a las nuevas condiciones (Atkinson et al. 1997; Martínez Ramos, 2004,2005).

Un cambio contable no debe ser visto sólo como la introducción de nuevos métodos contables que permitirán a los directivos tomar mejor sus decisiones, sino que el cambio incluye las alteraciones que éste produce en las prácticas o rutinas, actitudes, roles y en las responsabilidades de los miembros de la organización (Facin Lavarda, Ripoll Feliú \& Barrachina Palanca, 2009a; Facin Lavarda, Barrachina Palanca \& Ripoll Feliú, 2010) resaltan que la introducción de nuevos instrumentos o sistemas de CG en las PyMEs surgen por diversas razones: motivos de salud empresaria, motivos de competitividad y motivos de legitimación. En el primer caso, estos autores sostienen que diferentes estudios han encontrado que aquellas empresas que sufren una disminución en sus resultados o bien restricciones financieras, son más proclives a cambiar sus sistemas de CG a partir de la preocupación por la eficiencia económica y la mejora en la gestión de los costos. Por otro lado, la intensidad competitiva, la incertidumbre del entorno y la presencia en mercados internacionales, se han identificado como factores que promueven cambios en la CG, requiriendo mejorar la información necesaria para la toma de decisiones. El mayor nivel de competitividad, conlleva a un mayor nivel de exigencia en la oportunidad y relevancia de la información elaborada por los sistemas de gestión. Finalmente, cuando una organización detenta un alto grado de dependencia a la hora de obtener recursos de normas, reglas, preceptos dictados por diversas instituciones reguladoras de su entorno, la calidad de las relaciones institucionales que mantenga con el gobierno, entidades profesionales o empresariales, serán cruciales para el éxito (DiMaggio \& Powell, 1983; Oliver, 1991; Facin Lavarda, Barrachina Palanca \& Ripoll Feliú, 2010).

A los fines de entender la dinámica del cambio contable en las organizaciones, se ha contemplado a la CG como proceso, más que como resultado (Covaleski et. al, 1993; Burns \& Scapens, 2000; Martínez Ramos, 2005, Scapens, 2006). En la literatura sobre contabilidad gerencial, se han desarrollado en los últimos años diferentes modelos de estudio que tratan de 
entender y explicar particularmente por qué y cómo la contabilidad evoluciona, cómo lo hace a través del tiempo y operando en contextos organizaciones especiales. Estos modelos desde distintas perspectivas y enfoques teóricos, analizan los mecanismos y factores que intervienen en la adopción de innovaciones contables en las organizaciones (Shields \& Young, 1989; Innes \& Mitchel, 1990; Cobb, Helliar \& Innes, 1995; Bogt \& Helden, 2000; Martínez Ramos, 2004).

En la decisión de implantar una nueva herramienta contable intervienen múltiples elementos, tanto externos como internos. El cambio en la $\mathrm{CG}$ es un proceso complejo que implica la interacción de diferentes variables o elementos, de distinta naturaleza, donde la relación temporal de los distintos factores que originan los cambios, difieren significativamente.

Innes \& Mitchell (1990) interpretan el proceso de cambio mediante una clasificación de los factores o fuerzas originadores del cambio, basándose en la naturaleza y duración de su influencia, que sugiere las siguientes categorías:

- Facilitadores: Comprende las condiciones conducentes al cambio. Son factores necesarios para el cambio, pero no suficientes por ellos mismos. Por ejemplo: recursos del área contable, grado de autonomía de una casa matriz y la autoridad del personal contable.

- Motivadores: Son los que influyen para que se generen los cambios de un modo general. Ejemplo: un mercado competitivo, la tecnología de la producción, la estructura organizacional, un producto que tenga un ciclo de vida corto o la estructura de costos.

- Catalizadores: Son los que estarían asociados directamente con los cambios, pudiendo realizarse una correspondencia entre su aparición y el momento del cambio. Ejemplo: bajo rendimiento financiero, pérdida de cuota de mercado, la llegada de nuevo personal contable, lanzamiento de productos competidores y cambio organizacional.

Los factores facilitadores y catalizadores actuarían de manera positiva para generar el cambio en la CG, pero sólo podrían ser efectivos en la medida que se den las condiciones facilitadoras apropiadas.

Por su parte, el modelo de Cobb et al. (1995), si bien sostiene la existencia de los mencionados factores o fuerzas originadoras del cambio, agrega la consideración de:

- Barreras al cambio. Por ejemplo, la actitud de los gerentes hacia el cambio, cambio del personal del sector contable, cambios en las prioridades de los procesos internos, por un proyecto común o bien por el trabajo estratégico.

- El Lider, que recoge la influencia de los individuos sobre el cambio contable.

Este modelo reconoce la importancia de los líderes para superar las posibles barreras al cambio, y la necesidad de dar impulso para mantener el cambio a pesar de las resistencias.

Martínez Ramos (2005) destaca en un estudio realizado, la capacidad del modelo de cambio propuesto por Bogt \& Helden (2000) para explicar la adopción de un sistema de indicadores de gestión, y propone la ampliación del mismo para recoger el impacto del uso de nuevas herramientas de CG.

En la Figura 1, se presenta el modelo desarrollado por Bogt \& Helden (2000), que sostiene que el proceso de cambio en las empresas es originado por estímulos o presiones, tanto de fuentes internas como externas, que incluyen la cultura organizacional y las metas de la empresa. La figura del Líder es relevante, puesto que es consciente de la necesidad del cambio, con características de motivador y poder. Su accionar está afectado por la cultura de la organización en la que se desenvuelve, e intenta influir en los modos de acción de los 
individuos. Para analizar la viabilidad de los cambios deseados, toma en cuenta los hábitos y costumbres de los individuos que conforman la organización.

Según los autores citados, el proceso de implantación que se pretenda de la nueva herramienta es un proceso continuo. Para su aplicación, son necesarios varios favorecedores, tanto técnicos como organizacionales (capacitadores). Tras el proceso formal de implantación, sucede la implantación real, donde los integrantes de la organización comienzan a aceptar los nuevos instrumentos o herramientas, y de ser necesario pueden realizarse ajustes. Este modelo permite distinguir dos tipos de gap contable. Uno es el llamado gap de desarrollo, caracterizado por las diferencias que se puedan advertir por sus especificaciones técnicas, mientras que el otro tipo de gap, es denominado gap de uso y se vincula con las diferencias entre los instrumentos contables desarrollados y su uso en la práctica (Martínez Ramos, 2004,2005).

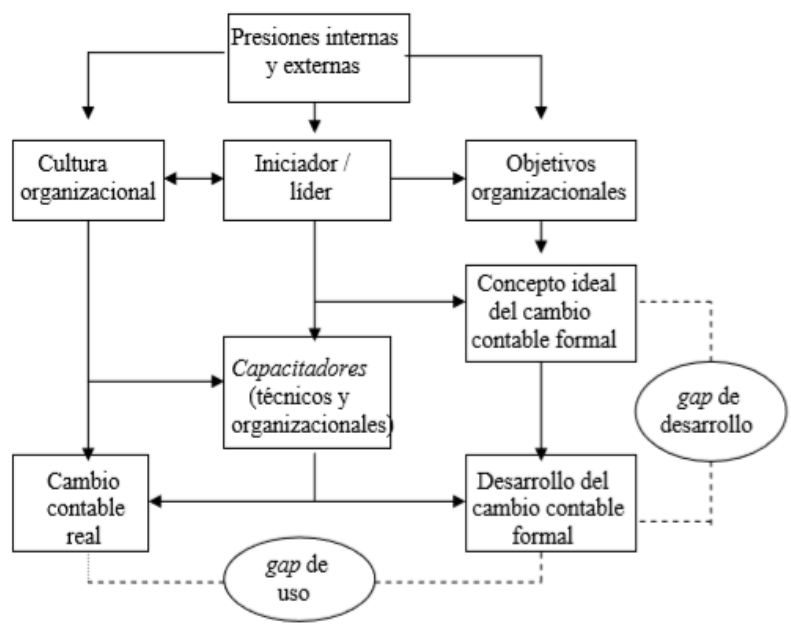

Figura 1. Modelo de cambio contable Fuente: Bogt \& Helden (2000).

Otros aportes en la literatura de CG se orientan a identificar los tipos de cambio contable que pueden ocurrir. Para el presente estudio, se adopta la tipología propuesta de Sulaiman \& Mitchel (2005) que permite definir el cambio de los sistemas de la CG en función de una serie de categorías que facilitan su análisis y comparación, las cuales se presentan a continuación en la Tabla 1. Al margen de lo anterior, un sexto tipo de cambio en las prácticas de control gerencial sería la propia ausencia de cambio, representada por la preferencia de una estabilidad en las prácticas actuales de control de gestión (Oyadomari et al., 2013). 
Tabla 1

Tipologías de cambios en prácticas de control gerencial

\begin{tabular}{|l|l|}
\hline Tipo de Cambio & Definición \\
\hline Adición & $\begin{array}{l}\text { Introducción de nuevas técnicas como extensión del sistema de } \\
\text { contabilidad gerencial, por ejemplo, costos de la gestión calidad, } \\
\text { incorporación de indicadores no monetarios. }\end{array}$ \\
\hline Reposición & $\begin{array}{l}\text { Introducción de nuevas técnicas como reposición de partes de técnicas } \\
\text { ya existentes, por ejemplo, presupuesto flexible con presupuesto fijo, } \\
\text { costeo por actividades dentro del sistema de costos. }\end{array}$ \\
\hline Modificación del Informe & $\begin{array}{l}\text { Modificación de la información relatada, por ejemplo, pasar de un } \\
\text { análisis mensual de las variaciones presupuestarias a uno semanal, o } \\
\text { cambiar la forma de presentación de informes, de numérica a una } \\
\text { mediante gráficos. }\end{array}$ \\
\hline Modificación Operacional & $\begin{array}{l}\text { Modificación de una operación técnica del sistema de contabilidad } \\
\text { gerencial, por ejemplo, el uso de la tasa predeterminada en oposición a } \\
\text { una tasa real, o el uso de análisis de regresión en lugar de análisis } \\
\text { separado de costes fijos y variables. }\end{array}$ \\
\hline Reducción & $\begin{array}{l}\text { Eliminación de una técnica de contabilidad gerencial sin reposición } \\
\text { por otra, por ejemplo, abandono del presupuesto o el análisis del punto } \\
\text { de equilibrio. }\end{array}$ \\
\hline Fuente: Adaptado de Sulaiman \& Mitchell (2005)y Oyadomari, de Aguiar, Chen \& Dultra-de-Lima (2013).
\end{tabular}

La CG está eminentemente implicada en el cambio, por eso la necesidad de su estudio, es resaltada en la literatura reciente sobre el tema. La CG evoluciona a través del tiempo y en contextos organizaciones específicos, siendo relevante conocer cómo son utilizados los nuevos instrumentos o prácticas gerenciales por los diferentes integrantes de la organización, y si dicho uso remodela la realidad empresarial, llegando a constituir nuevos modos de ver, pensar y actuar (Martínez Ramos, 2004,2005).

\section{METODOLOGIA}

El estudio empleó una metodología cualitativa basada en casos múltiples (Ayuso Moya \& Ripoll Feliú, 2005) sobre cuatro concesionarias de automóviles de la Argentina. El estudio de casos es un método de investigación que tiene por objetivo vislumbrar las conductas sociales por medio de la observación en profundidad, ya sea de agrupaciones, de individuos concretos o de parte o partes de una organización, teniendo una gran importancia en el desarrollo de las ciencias sociales.

Una de las principales ventajas del estudio de casos es su capacidad de explicar las causas del cambio y cómo se ha desarrollado en un determinado contexto organizativo (Araújo, 2003, citado por Facin Lavarda, Ripoll Feliú \& Barrachina Palanca, 2009b). Por cuanto permite una aproximación entre la teoría y la práctica (Yin, 1994; Ayuso Moya \& Ripoll Feliú, 2005).

Las técnicas de recolección de datos fueron: a) entrevistas formales semi estructuradas realizadas a los gerentes generales y mandos medios, que se complementaron con entrevistas informales; b) análisis de documentos que las empresas pusieron a disposición para el presente estudio, con el objetivo de obtener un mayor grado de confiabilidad de las informaciones aportadas por los entrevistados mediante un proceso de triangulación. Se relevaron documentos relativos a la estructura organizativa, procesos, normas internas, comunicaciones de política de las terminales, Informes Financieros y de Gestión e Informes de Auditorías de Gestión de las terminales; y finalmente, c) observación directa. 
Las concesionarias de marcas automotrices seleccionadas son cuatro PyMEs, constituidas como sociedades anónimas, de carácter familiar que integran un grupo empresarial del rubro automotor multimarca. Cada una de las empresas posee independencia en su administración económico-financiera. Su ámbito de actuación se encuentra al sur de la Provincia de Buenos Aires y en la Provincia de La Pampa en Argentina. Una de las firmas es concesionaria oficial de una tradicional marca americana y las tres restantes, son marcas de gestión europea. Se presenta a continuación en la Tabla 2, información general relevada sobre las cuatro concesionarias.

Las empresas bajo estudio presentan una estructura organizativa específica en función del tipo de negocio, donde las correspondientes funciones y responsabilidades se dividen por departamentos, según las actividades de la cadena de valor desarrolladas por la red comercial de las terminales automotrices, y que comprenden desde la venta a la postventa. La dirección de cada empresa establece a cada unidad organizativa los objetivos a cumplir y asigna los recursos a gestionar, de acuerdo a la estrategia empresarial alineada con la terminal. Por lo tanto, en cada concesionaria pueden reconocerse diferentes centros de responsabilidad. Los centros de responsabilidad son divisiones o segmentos de la empresa al frente de los cuales hay un responsable y a quienes se asignan objetivos concretos, cuyo cumplimiento tratará de obtenerse con un uso adecuado del sistema de control (Amat \& Campa, 2013). 
Tabla 2

Información General sobre los casos de estudio

\begin{tabular}{|c|c|c|c|c|}
\hline & Empresa "A" & Empresa "B" & Empresa "C" & Empresa "D" \\
\hline Comienzo de actividades & 1983 & 2000 & 2004 & 2007 \\
\hline Zona de Influencia & $\begin{array}{c}\text { Sur de la Provincia de } \\
\text { Buenos Aires (Casa Central) } \\
\text { y Provincia de La Pampa } \\
\text { (Sucursal) en Argentina. }\end{array}$ & $\begin{array}{c}\text { Sur de la Provincia de } \\
\text { Buenos Aires (Argentina). }\end{array}$ & $\begin{array}{l}\text { Provincia de La Pampa } \\
\text { (Argentina). }\end{array}$ & $\begin{array}{l}\text { Provincia de La Pampa } \\
\text { (Argentina). }\end{array}$ \\
\hline $\begin{array}{l}\text { ¿La gerencia está } \\
\text { profesionalizada? }\end{array}$ & Sí & No & Sí & No \\
\hline \multirow{5}{*}{$\begin{array}{l}\text { Herramientas de Gestión } \\
\text { Implementadas }\end{array}$} & $\begin{array}{l}\text { Sistema de información } \\
\text { integral contable y de } \\
\text { gestión diseñado a medida. }\end{array}$ & $\begin{array}{l}\text { Sistema de información } \\
\text { integral contable y de } \\
\text { gestión diseñado a medida. }\end{array}$ & $\begin{array}{c}\text { Sistema de información } \\
\text { integral contable y de } \\
\text { gestión diseñado a medida. }\end{array}$ & $\begin{array}{l}\text { Sistema de información } \\
\text { integral contable y de } \\
\text { gestión diseñado a medida. }\end{array}$ \\
\hline & $\begin{array}{l}\text { Estados Financieros y de } \\
\text { Gestión Mensuales. }\end{array}$ & $\begin{array}{c}\text { Estados Financieros y de } \\
\text { Gestión Trimestrales - } \\
\text { Acumulado. }\end{array}$ & $\begin{array}{l}\text { Estados Financieros y de } \\
\text { Gestión Trimestrales, con } \\
\text { información para cada mes y } \\
\text { acumulado a ese mes. }\end{array}$ & $\begin{array}{c}\text { Estados Financieros y de } \\
\text { Gestión Trimestrales - } \\
\text { Acumulado. }\end{array}$ \\
\hline & $\begin{array}{c}\text { Análisis de los Estados } \\
\text { Financieros en Sector } \\
\text { Servicios. }\end{array}$ & ---------- & $\begin{array}{l}\text { Análisis de los Estados } \\
\text { Financieros en Sector } \\
\text { Servicios. }\end{array}$ & $\begin{array}{c}\text { Análisis de los Estados } \\
\text { Financieros en Sector } \\
\text { Servicios. }\end{array}$ \\
\hline & $\begin{array}{l}\text { Indicadores de Gestión } \\
\text { Departamental e Índice de } \\
\text { Satisfacción al cliente. }\end{array}$ & 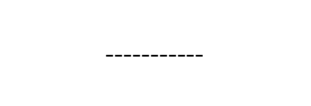 & $\begin{array}{l}\text { Indicadores de Gestión } \\
\text { Departamental e Índice de } \\
\text { Satisfacción al cliente. }\end{array}$ & $\begin{array}{l}\text { Indicadores de Gestión } \\
\text { Departamental. }\end{array}$ \\
\hline & $\begin{array}{l}\text { Planeamiento: Fijación de } \\
\text { objetivos de ventas. }\end{array}$ & & $\begin{array}{l}\text { Planeamiento: Fijación de } \\
\text { objetivos de ventas. }\end{array}$ & $\begin{array}{l}\text { Planeamiento: Fijación de } \\
\text { objetivos de ventas. }\end{array}$ \\
\hline $\begin{array}{l}\text { Documentos del Sistema } \\
\text { de Gestión de la Calidad }\end{array}$ & $\begin{array}{l}\text { A nivel Estratégico: Manual } \\
\text { de Calidad - A nivel } \\
\text { Táctico: Planes de Calidad. }\end{array}$ & ---------- & $\begin{array}{l}\text { A nivel Táctico: Planes } \\
\text { de Calidad. }\end{array}$ & $\begin{array}{l}\text { A nivel Táctico: Planes } \\
\text { de Calidad. }\end{array}$ \\
\hline $\begin{array}{l}\text { Procesos de } \\
\text { comunicación }\end{array}$ & $\begin{array}{c}\text { Reuniones entre } \\
\text { Directores/Propietarios y } \\
\text { Mandos Medios: formales e } \\
\text { informales. }\end{array}$ & $\begin{array}{c}\text { Reuniones entre } \\
\text { Directores/Propietarios y } \\
\text { Mandos Medios: } \\
\text { informales. }\end{array}$ & $\begin{array}{c}\text { Reuniones entre } \\
\text { Directores/Propietarios y } \\
\text { Mandos Medios: } \\
\text { informales. }\end{array}$ & $\begin{array}{c}\text { Reuniones entre } \\
\text { Directores/Propietarios y } \\
\text { Mandos Medios: } \\
\text { informales. }\end{array}$ \\
\hline Tamaño & Mediana - Tramo 1 & Pequeña & Mediana - Tramo 1 & Mediana - Tramo 1 \\
\hline
\end{tabular}

Fuente: Elaboración propia

Estos centros de responsabilidad son: Departamento de Nuevos (o tradicionales); Departamento de Plan de Ahorro; Departamento de Usados; Departamento de Repuestos y accesorios y Departamento de Servicio (o taller).

Se encontraron similitudes en las tipologías de centros de responsabilidad implantados, los cuales son definidos por las terminales automotrices para evaluar el desempeño de sus concesionarias de marca. En todos los casos analizados, las terminales de manera periódica, no sólo analizan el desempeño global de la empresa, sino que también miden los resultados de cada departamento en forma independiente.

En este sentido, cada terminal automotriz busca calificar no sólo la gestión económicafinanciera de las concesionarias, sino también su desempeño operativo periódicamente. Del análisis comparativo realizado con la documentación recabada, surge que el principal informe exigido por las terminales es el Estado Financiero y de Gestión. Su contenido brinda información analítica de la gestión global y de cada unidad de negocio (centro de responsabilidad) del concesionario. Su confección se ajusta a normas, procedimientos y 
planes de cuentas fijados por las terminales, con el objetivo de comparar resultados con otros concesionarios de similar estructura, y con los obtenidos por la media del país. Se espera asimismo que sean utilizados por las concesionarias en la toma de decisiones.

\section{RESULTADOS Y DISCUSION}

\subsection{Reporte de Evaluación de Desempeño de la Calidad}

En los últimos años, las terminales automotrices han promovido la renovación de prácticas gerenciales vinculadas a la gestión de la calidad en las PyMEs que integran la red comercial de concesionarias de su marca. Teniendo en cuenta que el servicio de post venta es considerado por las terminales un factor clave de éxito para la competitividad y atendiendo las dificultades que se plantean en esta fase de la cadena de valor de las concesionarias para lograr la excelencia del servicio en la experiencia del cliente, se ha desarrollado una propuesta de informe de costos e indicadores de calidad denominado Reporte de Evaluación de Desempeño de la Calidad para ser aplicado en principio en la actividades del Departamento de Servicio (Taller) (Tabla 3). A partir de la experiencia de su implementación se podrá luego extender a los restantes centros de responsabilidad.

Esta propuesta de reporte para el Departamento de Servicio (Taller) contempla para cada causal de costos de calidad (Actividades de Prevención, Actividades de Evaluación, Fallas internas y Fallas Externas), la cuantificación de cada uno de los conceptos de sacrificios económicos de factores que se derivan de ellas e indicadores financieros y no financieros para la evaluación de las actividades que afectan a estos costos. Se han definido responsables de su seguimiento y fuentes de información para el cálculo. Respecto a la oportunidad de emisión del reporte, se estableció una periodicidad mensual en el caso de la concesionaria oficial de marca americana y trimestral para el resto de las empresas, teniendo en cuenta la frecuencia con la que las terminales automotrices exigen la presentación del Estado Financiero y de Gestión.

La medición de costos e indicadores de calidad a través de un reporte integrado persigue contribuir a la planeación y el control, fundamentando las decisiones de mejora continua. El cambio que representa el diseño y uso del Reporte de Evaluación de Desempeño de la Calidad, siguiendo las tipologías preconizadas por Sulaiman \& Mitchell (2005) y Oyadomari et al. (2013), responde a un tipo de cambio por "adición", al introducir nuevas técnicas como extensión del sistema de CG vigente, en este caso, representadas por la determinación de costos de la calidad y de la no calidad, e información de indicadores complementarios.

Asimismo, participa de las características de un "cambio en la forma de presentación de las informaciones", dado que se ha modificado la frecuencia y el tipo de presentación de reportes para garantizar informaciones adecuadas al proceso decisorio. 
Casarsa, F. A. \& Scoponi, L. M..

Gestión de la calidad: una práctica gerencial para impulsar el cambio contable en pymes de redes comerciales automotrices de Argentina

Tabla 3

Reporte de Evaluación de Desempeño de la Calidad

REPORTE DE EVALUACION DE DESEMPEÑO DE LA CALIDAD 1. CONFORMIDADES (CALIDAD)

1.1. Actividades de Prevención

\begin{tabular}{|c|c|c|c|c|c|c|}
\hline 1.1.1. Costos & Mes Anterior & Mes Actual & $\% \mathrm{~s} /$ Total & $\% \mathrm{~s} / \mathrm{Vtas}$ & Presupuesto Mes & Desvio Presup. \\
\hline Costos de capacitación en calidad & & & $0 \%$ & $0 \%$ & 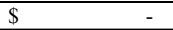 & $0 \%$ \\
\hline Costos de revisión & & & $0 \%$ & $0 \%$ & $\$$ & $0 \%$ \\
\hline Mantenimiento preventivo & & & $0 \%$ & $0 \%$ & $\$$ & $0 \%$ \\
\hline Programas de calidad impartidos por la terminal & & & $0 \%$ & $0 \%$ & $\$$ & $0 \%$ \\
\hline Total Costos de Prevención & $\$$ & \$ & $0 \%$ & $0 \%$ & $\$$ & $0 \%$ \\
\hline
\end{tabular}

Total Costos de Prevención

1.1.2. Indicadores Financieros

Total Costos de Prevención / Costos de Conformidades:

Total Costos de Prevención / TOTAL de Costos de Calidad:

\begin{tabular}{|c|c|c|c|c|c|}
\hline 1.1.3. Indicadores No Financieros & Objetivo & Fórmula & \begin{tabular}{|c|} 
Unidad \\
de medida
\end{tabular} & Responsable & Fuente \\
\hline Porcentaje de propuestas de acciones preventivas aprobadas & \begin{tabular}{|c|} 
"Aumentar el \\
porcentaje de \\
acciones preventivas \\
propuestas y \\
aprobadas"
\end{tabular} & $\begin{array}{c}\text { Número de acciones preventivas } \\
\text { aprobadas / Número de } \\
\text { propuestas preventivas } \\
\text { propuestas }\end{array}$ & $\%$ & Gerente de Servicio & $\begin{array}{l}\text { Informe Propuestas } \\
\text { y Acciones de } \\
\text { Mejora }\end{array}$ \\
\hline Porcentaje de acciones preventivas terminadas & \begin{tabular}{|} 
"Aumentar el \\
porcentaje de \\
acciones preventivas \\
implementadas"
\end{tabular} & $\begin{array}{c}\text { Número de acciones preventivas } \\
\text { terminadas / Sumatoria del } \\
\text { número de acciones preventivas } \\
\text { pendientes al incio y del número } \\
\text { de acciones preventivas } \\
\text { establecidas }\end{array}$ & $\%$ & Gerente de Servicio & $\begin{array}{l}\text { Informe de los } \\
\text { registros de No } \\
\text { Conformidades }\end{array}$ \\
\hline Número de reuniones realizadas con el personal & $\begin{array}{c}\text { "Realizar más } \\
\text { reuniones con el } \\
\text { personal" }\end{array}$ & $\begin{array}{c}\text { Número de reuniones realizadas } \\
\text { con el personal }\end{array}$ & $\begin{array}{c}\mathrm{N}^{o} \text { de } \\
\text { reuniones }\end{array}$ & Gerente de Servicio & $\begin{array}{l}\text { Informe de } \\
\text { Reuniones }\end{array}$ \\
\hline $\begin{array}{l}\text { Porcentaje de participación en Capacitaciones "Cursos } \\
\text { Presenciales }\end{array}$ & $\begin{array}{l}\text { "Cumplir las } \\
\text { capacitaciones } \\
\text { presenciales } \\
\text { asignadas" }\end{array}$ & $\begin{array}{l}\text { Número de Capacitaciones } \\
\text { Presenciales realizadas / } \\
\text { Número de capacitaciones } \\
\text { presenciales programadas. }\end{array}$ & $\%$ & Gerente de Servicio & $\begin{array}{l}\text { Programa de } \\
\text { capacitaciones }\end{array}$ \\
\hline Porcentaje de aprobación de Capacitaciones "Cursos Web & $\begin{array}{l}\text { "Cumplir y aprobar } \\
\text { los cursos Web } \\
\text { estipulados por la } \\
\text { terminal" }\end{array}$ & $\begin{array}{c}\text { Número de Cursos WEB } \\
\text { aprobados / Número de } \\
\text { Capacitaciones: Cursos WEB } \\
\text { programadas }\end{array}$ & $\%$ & Gerente de Servicio & $\begin{array}{l}\text { Programa de } \\
\text { capacitaciones }\end{array}$ \\
\hline $\begin{array}{l}\text { Grado de cumplimiento del programa de mantenimiento de los } \\
\text { equipos }\end{array}$ & $\begin{array}{l}\text { "Cumplir con el } \\
\text { Programa de } \\
\text { Mantenimiento de } \\
\text { los Equipos" }\end{array}$ & $\begin{array}{l}\text { Número de equipos que } \\
\text { recibieron correctamente } \\
\text { mantenimiento / Número de } \\
\text { equipos que requerian } \\
\text { mantenimiento }\end{array}$ & $\%$ & Gerente de Servicio & $\begin{array}{l}\text { Registro del } \\
\text { Programa de } \\
\text { Mantenimiento de } \\
\text { los equipos }\end{array}$ \\
\hline
\end{tabular}

\subsection{Actividades de Evaluación}

\begin{tabular}{|c|c|c|c|c|c|c|c|c|}
\hline 1.2.1. Costos & & & & & $\% \mathrm{~s} /$ Total & $\% \mathrm{~s} / \mathrm{Vtas}$ & Presupuesto Mes & Desvío Presup. \\
\hline - Costos de auditorías y revisión de la calidad del sector & $\$$ & - & $\$$ & - & $0 \%$ & $0 \%$ & $\$ \quad-$ & $0 \%$ \\
\hline - Inspección y pruebas en órdenes de reparación & $\$$ & - & $\$$ & - & $0 \%$ & $0 \%$ & $\$$ & $0 \%$ \\
\hline - Costos asignados del Departamento de calidad & $\$$ & - & $\$$ & - & $0 \%$ & $0 \%$ & $\$$ & $0 \%$ \\
\hline - Costos de inspecciones & $\$$ & - & $\$$ & - & $0 \%$ & $0 \%$ & $\$$ & $0 \%$ \\
\hline - Verificación de la precisión de los equipos y herramientas & $\$$ & - & $\$$ & - & $0 \%$ & $0 \%$ & $\$$ & $0 \%$ \\
\hline - Costos en Certificación. & $\$$ & - & $\$$ & - & $0 \%$ & $0 \%$ & $\$$ & $0 \%$ \\
\hline Total Costos de Evaluación & $\$$ & - & $\$$ & - & $0 \%$ & $0 \%$ & $\$$ & $0 \%$ \\
\hline
\end{tabular}

\subsubsection{Indicadores Financieros}

\begin{tabular}{|l|l|}
\hline Total Costos de Evaluación / Costos de Conformidades: & \\
\hline Total Costos de Evaluación / TOTAL Costos de Calidad: & \\
\hline
\end{tabular}

\begin{tabular}{|c|c|c|c|c|c|}
\hline 1.2.3. Indicadores No Financieros & Objetivo & Fórmula & \begin{tabular}{|c|} 
Unidad \\
de medida
\end{tabular} & Responsable & Fuente \\
\hline Porcentaje de iniciativas implementadas & $\begin{array}{c}\text { "Mejorar el } \\
\text { porcentaje de } \\
\text { iniciativas } \\
\text { implementadas" }\end{array}$ & $\begin{array}{l}\text { Número de iniciativas } \\
\text { implementadas / Número de } \\
\text { iniciativas aprobadas }\end{array}$ & $\%$ & Gerente de Servicio & $\begin{array}{l}\text { Informe Propuestas } \\
\text { y Acciones de } \\
\text { Mejora }\end{array}$ \\
\hline Porcentaje de acciones correctivas terminadas & $\begin{array}{c}\text { "Aumentar el } \\
\text { porcentaje de } \\
\text { acciones correctivas } \\
\text { implementadas" }\end{array}$ & $\begin{array}{c}\text { Número de acciones correctivas } \\
\text { terminadas / Sumatoria del } \\
\text { número de acciones correctivas } \\
\text { pendientes al incio y del número } \\
\text { de acciones correctivas } \\
\text { establecidas }\end{array}$ & $\%$ & Gerente de Servicio & $\begin{array}{l}\text { Informe de los } \\
\text { registros de No } \\
\text { Conformidades }\end{array}$ \\
\hline
\end{tabular}


Casarsa, F. A. \& Scoponi, L. M..

Gestión de la calidad: una práctica gerencial para impulsar el cambio contable en pymes de redes comerciales automotrices de Argentina

\section{(Continuación)}

\begin{tabular}{|c|c|c|c|c|c|}
\hline Porcentaje de unidades entregadas en la fecha acordada & \begin{tabular}{|c|} 
"Mejorar el \\
porcentaje de \\
unidades entregadas \\
en la fecha \\
acordada" \\
\end{tabular} & $\begin{array}{l}\text { Número de vehículos } \\
\text { entregados en la fecha acordada } \\
\text { / Número de vehículos } \\
\text { entregados. }\end{array}$ & $\%$ & Gerente de Servicio & $\begin{array}{c}\text { Informe de unidades } \\
\text { entregadas }\end{array}$ \\
\hline Número de unidades entregadas sin la revisión de entrega & $\begin{array}{c}\text { "Disminuir el } \\
\text { número de unidades } \\
\text { entregadas sin } \\
\text { revisión" }\end{array}$ & $\begin{array}{l}\text { Número de unidades entregadas } \\
\text { sin revisión / Número de } \\
\text { unidades entregadas }\end{array}$ & $\%$ & Gerente de Servicio & $\begin{array}{c}\text { Informe de unidades } \\
\text { entregadas }\end{array}$ \\
\hline $\begin{array}{l}\text { Grado de cumplimiento del Programa de medición y } \\
\text { seguimiento de los equipos de taller }\end{array}$ & \begin{tabular}{|c|} 
"Cumplir con el \\
Programa de Control \\
de los Equipos de \\
Medicion y \\
Seguimiento"
\end{tabular} & $\begin{array}{l}\text { Número de equipos que se } \\
\text { controlaron / Número de } \\
\text { equipos que requerían control }\end{array}$ & $\%$ & Gerente de Servicio & $\begin{array}{c}\text { Registros en el } \\
\text { Programa de Control } \\
\text { de los equipos de } \\
\text { Medicion y } \\
\text { Seguimiento }\end{array}$ \\
\hline
\end{tabular}

\section{NO CONFORMIDADES (NO CALIDAD)}

\subsection{Actividades de Falla Interna}

\begin{tabular}{|c|c|c|c|c|c|c|c|c|}
\hline 2.1.1. Costos & & & & & $\% \mathrm{~s} /$ Total & $\%$ s/Vtas & Presupuesto Mes & Desvío Presup. \\
\hline Insumos desaprovechados & $\$$ & - & $\$$ & - & $0 \%$ & $0 \%$ & $\$ \quad-$ & $0 \%$ \\
\hline \begin{tabular}{|l|} 
Costos de reprocesos o retrabajos \\
\end{tabular} & $\$$ & - & $\$$ & - & $0 \%$ & $0 \%$ & $\$$ & $0 \%$ \\
\hline Pérdida de tiempo & $\$$ & - & $\$$ & - & $0 \%$ & $0 \%$ & $\$$ & $0 \%$ \\
\hline Errores en el mantenimiento de los equipos & $\$$ & - & $\$$ & - & $0 \%$ & $0 \%$ & $\$$ & $0 \%$ \\
\hline Mantenimiento correctivo & $\$$ & - & $\$$ & - & $0 \%$ & $0 \%$ & $\$$ & $0 \%$ \\
\hline Costos financieros por cobros fuera de término & $\$$ & - & $\$$ & - & $0 \%$ & $0 \%$ & $\$$ & $0 \%$ \\
\hline Total Costos de Falla Interna & $\$$ & - & $\$$ & - & $0 \%$ & $0 \%$ & $\$$ & $0 \%$ \\
\hline
\end{tabular}

\subsubsection{Indicadores Financieros}

Evolución de los costos directos de fallas internas

\begin{tabular}{|c|c|c|c|}
\hline Objetivo & Herramienta & Responsable & Fuente \\
\hline $\begin{array}{c}\text { "Disminuir los } \\
\text { costos de falla } \\
\text { interna" }\end{array}$ & Gráfico de tendencia & Gerente de Servicio & Sistema contable \\
\hline
\end{tabular}

\begin{tabular}{|l} 
2.1.3. Indicadores No Financieros \\
$\begin{array}{l}\text { Porcentaje de órdenes de reparación que corresponden a re- } \\
\text { trabajos }\end{array}$ \\
\hline Período promedio de cobranza
\end{tabular}

\begin{tabular}{|c|c|c|c|c|}
\hline Objetivo & Fórmula & $\begin{array}{c}\text { Unidad } \\
\text { de medida }\end{array}$ & Responsable & Fuente \\
\hline $\begin{array}{c}\text { "Reducir el } \\
\text { porcentaje de } \\
\text { Ordenes de } \\
\begin{array}{c}\text { Reparación } \\
\text { correspondientes a } \\
\text { retrabajos" }\end{array}\end{array}$ & $\begin{array}{c}\text { Número de Ordenes de } \\
\text { Reparacion que corresponden a }\end{array}$ & $\%$ & Gerente de Servicio & $\begin{array}{c}\text { Informe de tipos de } \\
\text { reparaciones }\end{array}$ \\
\hline $\begin{array}{c}\text { "Reducir el período } \\
\text { promedio de } \\
\text { cobranza" }\end{array}$ & & & Gerente de Servicio & Sistema contable \\
\hline
\end{tabular}

\subsection{Actividades de Falla Externa}

\begin{tabular}{|c|c|c|c|c|c|c|}
\hline 2.2.1. Costos & Mes Anterior & Mes Actual & \multirow{2}{*}{$\frac{\% \text { s/Total }}{0 \%}$} & \multirow{2}{*}{$\frac{\% \mathbf{s} / \mathrm{Vtas}}{0 \%}$} & Presupuesto Mes & \multirow{2}{*}{$\begin{array}{c}\text { Desvio Presup. } \\
0 \% \\
\end{array}$} \\
\hline Costo de los servicios post-venta mal realizados & $\$ \quad-$ & $\$ \$ \quad-$ & & & $\$ \quad-$ & \\
\hline Atención de reclamos de clientes & $\$$ & $\$$ & $0 \%$ & $0 \%$ & $\$$ & $0 \%$ \\
\hline Gastos y honorarios judiciales & $\$$ & $\$$ & $0 \%$ & $0 \%$ & - & $0 \%$ \\
\hline Indemnizaciones a pagar a los clientes & $\$$ & $\$$ & $0 \%$ & $0 \%$ & $\$$ & $0 \%$ \\
\hline Devoluciones y Garantías & $\$$ & $\$$ & $0 \%$ & $0 \%$ & - & $0 \%$ \\
\hline Ajustes fuera de garantía. & $\$$ & $\$$ & $0 \%$ & $0 \%$ & $\$$ & $0 \%$ \\
\hline Descuentos o Bonificaciones otorgadas por defectos & $\$$ & $\$$ & $0 \%$ & $0 \%$ & $\$$ & $0 \%$ \\
\hline Ventas perdidas relacionadas con la satisfacción de clientes & $\$$ & $\$$ & $0 \%$ & $0 \%$ & $\$$ & $0 \%$ \\
\hline Total Costos de Falla Externa & $\$$ & $\$$ & $\mathbf{0 \%}$ & $\mathbf{0 \%}$ & $\$$ & $\mathbf{0 \%}$ \\
\hline 2.2.2. Indicadores Financieros & Objetivo & \multicolumn{3}{|c|}{ Herramienta } & Responsable & Fuente \\
\hline Evolución de los costos directos de fallas externas & $\begin{array}{c}\text { "Disminuir los } \\
\text { costos de falla } \\
\text { externa" }\end{array}$ & \multicolumn{3}{|c|}{ Gráfico de tendencia } & Gerente de Servicio & Sistema contable \\
\hline 2.2.3. Indicadores No Financieros & Objetivo & \multicolumn{2}{|c|}{ Fórmula } & $\begin{array}{c}\text { Unidad } \\
\text { de medida }\end{array}$ & Responsable & Fuente \\
\hline Porcentaje de reclamos de garantía aprobados & $\begin{array}{c}\text { "Aumentar el } \\
\text { número de reclamos } \\
\text { de garantia } \\
\text { aprobados por la } \\
\text { terminal" }\end{array}$ & \multicolumn{2}{|c|}{$\begin{array}{l}\text { Número de reclamos realizados } \\
\text { aprobados / Número de } \\
\text { reclamos realizados }\end{array}$} & $\%$ & $\begin{array}{l}\text { Responsable de } \\
\text { Garantías }\end{array}$ & Informe de reclamos \\
\hline Porcentaje de reclamos de clientes resueltos & $\begin{array}{l}\text { "Incrementar el } \\
\text { número de quejas } \\
\text { resueltas" }\end{array}$ & \multicolumn{2}{|c|}{$\begin{array}{c}\text { Número de reclamos o quejas } \\
\text { de clientes resueltos / Número } \\
\text { total de reclamos o quejas } \\
\text { recibidas }\end{array}$} & $\%$ & Gerente de Servicio & $\begin{array}{l}\text { Sistema de } \\
\text { Informacion de } \\
\text { calidad }\end{array}$ \\
\hline $\begin{array}{l}\text { Número de clientes atendidos por reparación cargo cliente que ya } \\
\text { acudieron al taller durante el período de garantía }\end{array}$ & $\begin{array}{c}\text { "Incrementar el } \\
\text { número de clientes } \\
\text { que continúan } \\
\text { asistiendo al taller } \\
\text { luego del período de } \\
\text { garantía" }\end{array}$ & \multicolumn{2}{|c|}{$\begin{array}{l}\text { Número de clientes atendidos } \\
\text { por reparaciones cargo cliente } \\
\text { que ya acudieron al taller } \\
\text { durante el período de garantía. }\end{array}$} & $\begin{array}{l}\mathrm{N}^{\circ} \text { de } \\
\text { clientes }\end{array}$ & Gerente de Servicio & $\begin{array}{c}\text { Informe de Clientes } \\
\text { atendidos. }\end{array}$ \\
\hline
\end{tabular}


(Continuación)

\begin{tabular}{|c|c|c|c|c|c|c|}
\hline \multicolumn{7}{|c|}{ REPORTE DE EVALUACION DE DESEMPEÑO DE LA CALIDAD } \\
\hline RESUMEN & Mes Anterior & Mes Actual & $\% \mathrm{~s} /$ Total & $\% \mathrm{~s} /$ Vtas. & Presupuesto Me & Desvio Presup. \\
\hline 1.1. Total Costos de Prevención & $\$$ & $\$$ & $0 \%$ & $0 \%$ & $\$ \$ \quad-1$ & $0 \%$ \\
\hline 1.2. Total Costos de Evaluación & $\$$ & $\$$ & $0 \%$ & $0 \%$ & $\$$ & $0 \%$ \\
\hline TOTAL COSTOS de CALIDAD (CONFORMIDAD) & $\$$ & $\$$ & $\mathbf{0 \%}$ & $\mathbf{0 \%}$ & $\$$ & $\mathbf{0 \%}$ \\
\hline 2.1. Total Costos de Fallas Internas & $\$$ & $\$$ & $0 \%$ & $0 \%$ & $\$$ & $0 \%$ \\
\hline 2.2. Total Costos de Fallas Externas & $\$$ & $\$$ & $0 \%$ & $0 \%$ & $\$$ & $0 \%$ \\
\hline TOTAL COSTOS de NO CALIDAD (NO CONFORMIDAD) & $\$$ & $\$$ & $0 \%$ & 0\% & $\$$ & $0 \%$ \\
\hline TOTAL COSTOS DE CALIDAD & $\$$ & $\$$ & $0 \%$ & $0 \%$ & $\$$ & $\mathbf{0 \%}$ \\
\hline \multicolumn{7}{|l|}{ Balance: Total Costos Calidad / Total Costos No Calidad } \\
\hline & Objetivo & \multicolumn{2}{|c|}{ Fórmula } & $\begin{array}{c}\text { Unidad } \\
\text { de medida }\end{array}$ & Responsable & Fuente \\
\hline Indice de Satisfacción de los clientes & $\begin{array}{l}\text { "Aumentar el Indice } \\
\text { de Satisfacción de } \\
\text { los clientes" }\end{array}$ & \multicolumn{2}{|c|}{$\begin{array}{c}\text { Número de Encuestas positivas } \\
\text { / Número de encuestas } \\
\text { realizadas }\end{array}$} & $\%$ & $\begin{array}{c}\text { Gerente de } \\
\text { Servicio }\end{array}$ & $\begin{array}{c}\text { Informe de resultados de } \\
\text { Encuestas de Calidad de } \\
\text { los Servicios de } \\
\text { Postventa }\end{array}$ \\
\hline
\end{tabular}

Fuente: Elaboración propia.

\subsection{Análisis de los factores influyentes en la implementación del reporte propuesto}

Atendiendo lo expuesto en secciones anteriores, la problemática de la calidad, se ha convertido en un factor clave de las auditorias de gestión que realizan periódicamente las terminales automotrices a las empresas de su red comercial. En este sentido, el Reporte de Evaluación de Desempeño de la Calidad brinda a la dirección y a los gerentes información oportuna y sistematizada de los costos de calidad que puede favorecer la interiorización y la mejora de los procesos en los negocios más significativos que las terminales exigen. El centro de responsabilidad puede disponer de un detalle de los costos que se generan y de indicadores específicos para el control de gestión, de modo de promover, al contar con dicha información, la institucionalización de las nuevas prácticas gerenciales requeridas por las terminales automotrices y el consecuente cambio en la CG para ajustarse, en un ciclo virtuoso, a dichas condiciones, como lo expresa Martínez Ramos (2005). En virtud de ello, en los casos analizados, el cambio en la CG se da por legitimación, frente a la dependencia de recursos y la regulación de normas de actuación que imponen las terminales.

Por otra parte, las PyMEs analizadas deben hacer frente a su entorno competitivo en donde, la información referida a la administración de calidad es fundamental para su supervivencia y crecimiento, pero también a los fines de su control de gestión interno. Esto es coincidente con los hallazgos de Facin Lavarda, Barrachina Palanca \& Ripoll Feliú (2010) que encontraron que la salud empresarial y la competitividad son motivos que llevan a la PyME a cambiar su sistema contable de gestión, además de la legitimación. En los casos que se analizan en el presente estudio se ha contemplado la dinámica del cambio como un proceso, más que como resultado (Covaleski et. al, 1993; Burns \& Scapens, 2000; Martínez Ramos, 2005 Scapens, 2006). En consecuencia, el estudio identifica la forma en que puede ser utilizado el nuevo instrumento para evaluar si dicho uso permitiría renovar las prácticas gerenciales (Martínez Ramos, 2005).

Para categorizar los factores que influyen en la adopción de esta innovación, se emplearon los aportes de Cobb et al. (1995) y de Bogt \& Helden (2000), siguiendo el enfoque de análisis sugerido por Martínez Ramos $(2004,2005)$ para ampliar las posibles fuerzas originadoras del cambio en la CG, al integrar ambos modelos. Así, se han identificado factores catalizadores, motivadores, facilitadores y barreras al cambio, donde un líder recoge la influencia de los individuos sobre el cambio contable. En la Tabla 4 se resumen los principales factores que, según lo observado en las PyMEs bajo estudio, tienen una influencia 
Casarsa, F. A. \& Scoponi, L. M..

Gestión de la calidad: una práctica gerencial para impulsar el cambio contable en pymes de redes comerciales automotrices de Argentina

relevante en la implantación, uso y posterior repercusión organizativa del nuevo instrumento de práctica gerencial bajo el modelo mencionado.

Tabla 4

Factores que influyen en el cambio contable de las empresas bajo estudio

\begin{tabular}{|c|c|c|}
\hline \multirow{7}{*}{ 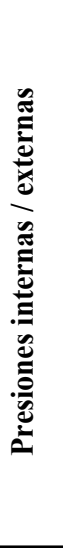 } & \multirow{4}{*}{ 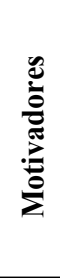 } & $\begin{array}{l}\text { Una marcada tendencia hacia la homogeneización de las prácticas de CG motivada por } \\
\text { presiones competitivas e institucionales por parte de las terminales. }\end{array}$ \\
\hline & & El aumento de la competitividad en el sector. \\
\hline & & Convicción y compromiso de los propietarios/directores en mejorar la gestión. \\
\hline & & $\begin{array}{l}\text { La calificación de los mandos medios y la profesionalización de la gestión, que demandan } \\
\text { más y mejor información para la toma de decisiones. }\end{array}$ \\
\hline & \multirow{3}{*}{ 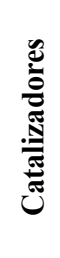 } & $\begin{array}{l}\text { El aumento de la competitividad en la venta de vehículos nuevos, con la consiguiente } \\
\text { reducción de márgenes, impulsa al Departamento de Servicio como sector clave para la } \\
\text { mejora de la rentabilidad de la empresa. }\end{array}$ \\
\hline & & La implantación de Sistemas de Gestión de la Calidad por parte de las terminales \\
\hline & & $\begin{array}{l}\text { La implicación de los dueños/directores derivada de las mejoras logradas en otras empresas } \\
\text { de la red comercial. }\end{array}$ \\
\hline \multicolumn{2}{|c|}{ íder } & $\begin{array}{l}\text { Nivel gerencial con un fuerte compromiso e involucramiento, conjuntamente con los } \\
\text { propietarios/directores de las empresas. }\end{array}$ \\
\hline \multirow{16}{*}{ 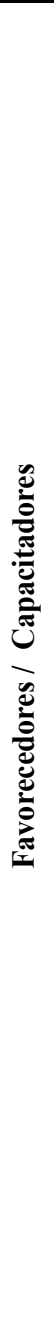 } & \multirow{8}{*}{ 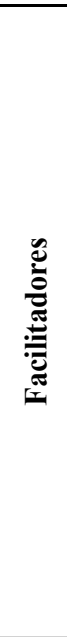 } & $\begin{array}{l}\text { La generación de información relevante y oportuna referida a los costos de calidad para la } \\
\text { toma de decisiones, a partir del conocimiento de las causas de los mismos, el análisis de la } \\
\text { eficacia y eficiencia en la gestión de la calidad, para lograr mejoras en las medidas de } \\
\text { desempeño alineadas con la estrategia de la terminal. }\end{array}$ \\
\hline & & $\begin{array}{l}\text { Los Programas de Calidad de las terminales definidos para los distintos sectores o } \\
\text { departamentos de las concesionarias, y las visitas periódicas de auditorías del Sistema de } \\
\text { Gestión de Calidad. }\end{array}$ \\
\hline & & $\begin{array}{l}\text { La existencia de un sistema de informacion integrado que recolecta información financiera y } \\
\text { no financiera vinculada a las distintas unidades de negocio de las concesionarias }\end{array}$ \\
\hline & & Convicción y compromiso de los propietarios/directores. \\
\hline & & Reuniones entre propietarios/directores y mandos gerenciales más frecuentes. \\
\hline & & Niveles gerenciales más autónomos, a partir de su grado de profesionalización. \\
\hline & & Intervención de consultores externos para acompañar el cambio. \\
\hline & & Profesionalización del área administrativa-contable y de auditoría. \\
\hline & & $\begin{array}{l}\text { La recolección de datos para el Reporte incrementa el trabajo administrativo, es decir causa } \\
\text { trabajo extra en el personal del sector y también en el área administrativa-contable. }\end{array}$ \\
\hline & & $\begin{array}{l}\text { Deficiencia del sistema integral para brindar algunos datos necesarios para el Reporte, dado } \\
\text { que incrementa requerimientos de información específica que conlleva una adecuación del } \\
\text { sistema. }\end{array}$ \\
\hline & 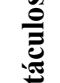 & $\begin{array}{l}\text { Incrementa el trabajo del nivel gerencial, dado que debe dedicarse tiempo al análisis de los } \\
\text { costos e indicadores de calidad de manera periódica. }\end{array}$ \\
\hline & $\frac{\bar{s}}{\overline{0}_{0}}$ & $\begin{array}{l}\text { Falta de conocimientos y capacitación en "costos" de los niveles gerenciales a partir de } \\
\text { perfiles de distintas áreas de formación profesional lo cual puede repercutir en no } \\
\text { aprovechar todo el potencial ofrecido por el Reporte. }\end{array}$ \\
\hline & 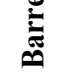 & $\begin{array}{l}\text { Falta de convencimiento e interés en algunos integrantes del personal del sector sobre los } \\
\text { beneficios del Reporte originada en problemas de comunicación. }\end{array}$ \\
\hline & & Falta de especialistas en temas de calidad dentro del personal estable de la organización. \\
\hline & & Falta de recursos apropiados (personal, instalaciones, etc). \\
\hline & & $\begin{array}{l}\text { Signos de resistencia al cambio dentro de la organización, motivadas por la natural } \\
\text { resistencia al cambio y a sentirse controlados. }\end{array}$ \\
\hline
\end{tabular}

Fuente: Elaboración propia.

Management Control Review, v. 5, n. 2, Jul/Dez, pp. 40-60, 2020. ISSN 2526-1282. 
Del análisis realizado se observa que los factores facilitadores que apoyan el cambio en las empresas bajo estudio son principalmente, los Programas de Calidad de las terminales que deben cumplirse en todas las unidades de negocio, lo que conlleva que esta política de las terminales tiene como objetivo lograr la mejora de procesos a través del esfuerzo de cada uno de los sectores, fijando pautas para llevar a cabo tareas, tiempos, documentación, e informes que luego controlan en visitas de auditorías periódicas.

La existencia de un sistema de información integrado que recolecta información financiera y no financiera vinculada a las distintas unidades de negocio de las concesionarias (Departamentos), demuestra que los desarrollos y las inversiones en tecnologías de información, generan condiciones propicias para desarrollar cambios en la CG.

En este sentido se observa la convicción y el compromiso de los propietarios/directores, dado que el sistema integral de información para la gestión, fue diseñado a medida por uno de ellos, atendiendo sus necesidades y codificando las políticas de las terminales para apoyar la administración de cada uno de los Departamentos, generando actividades internas de gestión y control que pudieran vincularse con los objetivos globales de la organización.

De la información obtenida, se puede apreciar que los principales beneficios que se perciben por la adopción del reporte fundamentalmente se asocian a contar con información organizada y ordenada bajo otros criterios que los requeridos en los Estados Financieros y de Gestión con el propósito de agrupar los costos de calidad, identificando claramente los costos de conformidades versus los costos de no conformidades, y de establecer nuevas medidas de desempeño. Los gerentes del sector pueden emplear esta información para evaluar los beneficios en costos e ingresos derivados de las iniciativas de la administración de la calidad, y a su vez para cumplimentar más satisfactoriamente los Programas de Calidad de las terminales definidos y las visitas periódicas de auditorías del Sistema de Gestión de Calidad. Asimismo, el análisis y seguimiento de nuevos indicadores para el sector se reconoce que mejora las comunicaciones con la dirección y con los subordinados para señalar los aspectos clave de la gestión. Se pudo advertir en la empresa "A", la primera empresa fundada del grupo y la de mayor tamaño en cuanto a facturación anual y cantidad de empleados, que existen algunos procesos de comunicación formal de las salidas del sistema de información de gestión y de los resultados de estas evaluaciones o auditorias de gestión a los mandos gerenciales, pero no constituyen prácticas de gestión enraizadas en la cultura organizacional.

Por su parte, el análisis realizado muestra que las principales barreras u obstáculos que deben afrontar las empresas para adoptar el nuevo instrumento de la CG son: el incremento de trabajo administrativo y la falta de especialistas en temas de calidad dentro del staff. Esto último se detectó en dos de las cuatro empresas bajo estudio.

Se observa que los agentes impulsores del cambio, con un elevado grado de compromiso e implicación, son los gerentes que proporcionan apoyo a las acciones necesarias para la mejora de la calidad de los servicios prestados y a la optimización del resultado del sector que impulsa mejoras de rentabilidad de la organización. Se destacan en la gestión, pasando a asumir posiciones de liderazgo, debido a la importancia estratégica de la calidad.

Sin embargo, es de destacar que a partir de la información relevada la calificación de los mandos medios y su grado de profesionalización resulta un factor clave para incorporar como rutina el uso del Reporte diseñado. Es decir, los conocimientos y habilidades de los gerentes del Departamento de Servicio (Taller) se identificaron tanto como barreras así como facilitadores, siendo fundamentales para el análisis y discusión de los resultados. Por ejemplo, la concesionaria de mayor tamaño tiene desde el año 2008 sus gerencias comercial y administrativa con personal profesional y capacitado para el puesto de trabajo, observándose mejoras en la interpretación y uso de la información del sistema integral contable y de los 
Estados Financieros y de Gestión, complemento necesario del Reporte de Evaluación de Desempeño de la Calidad. Esta condición ya fue resaltada por Facin Lavarda et al. (2009a, $2009 b$ ) en sus investigaciones.

\section{CONSIDERACIONES FINALES}

Del análisis realizado se observa que los factores facilitadores que apoyan el cambio en las empresas bajo estudio son principalmente, los Programas de Calidad de las terminales que deben cumplirse en todas las unidades de negocio, lo que conlleva que esta política de las terminales tiene como objetivo lograr la mejora de procesos a través del esfuerzo de cada uno de los sectores, fijando pautas para llevar a cabo tareas, tiempos, documentación, e informes que luego controlan en visitas de auditorías periódicas.

La existencia de un sistema de información integrado que recolecta información financiera y no financiera vinculada a las distintas unidades de negocio de las concesionarias (Departamentos), demuestra que los desarrollos y las inversiones en tecnologías de información, generan condiciones propicias para desarrollar cambios en la CG.

En este sentido se observa la convicción y el compromiso de los propietarios/directores, dado que el sistema integral de información para la gestión, fue diseñado a medida por uno de ellos, atendiendo sus necesidades y codificando las políticas de las terminales para apoyar la administración de cada uno de los Departamentos, generando actividades internas de gestión y control que pudieran vincularse con los objetivos globales de la organización.

De la información obtenida, se puede apreciar que los principales beneficios que se perciben por la adopción del reporte fundamentalmente se asocian a contar con información organizada y ordenada bajo otros criterios que los requeridos en los Estados Financieros y de Gestión con el propósito de agrupar los costos de calidad, identificando claramente los costos de conformidades versus los costos de no conformidades, y de establecer nuevas medidas de desempeño. Los gerentes del sector pueden emplear esta información para evaluar los beneficios en costos e ingresos derivados de las iniciativas de la administración de la calidad, y a su vez para cumplimentar más satisfactoriamente los Programas de Calidad de las terminales definidos y las visitas periódicas de auditorías del Sistema de Gestión de Calidad. Asimismo, el análisis y seguimiento de nuevos indicadores para el sector se reconoce que mejora las comunicaciones con la dirección y con los subordinados para señalar los aspectos clave de la gestión. Se pudo advertir en la empresa "A", la primera empresa fundada del grupo y la de mayor tamaño en cuanto a facturación anual y cantidad de empleados, que existen algunos procesos de comunicación formal de las salidas del sistema de información de gestión y de los resultados de estas evaluaciones o auditorias de gestión a los mandos gerenciales, pero no constituyen prácticas de gestión enraizadas en la cultura organizacional.

Por su parte, el análisis realizado muestra que las principales barreras u obstáculos que deben afrontar las empresas para adoptar el nuevo instrumento de la CG son: el incremento de trabajo administrativo y la falta de especialistas en temas de calidad dentro del staff. Esto último se detectó en dos de las cuatro empresas bajo estudio.

Se observa que los agentes impulsores del cambio, con un elevado grado de compromiso e implicación, son los gerentes que proporcionan apoyo a las acciones necesarias para la mejora de la calidad de los servicios prestados y a la optimización del resultado del sector que impulsa mejoras de rentabilidad de la organización. Se destacan en la gestión, pasando a asumir posiciones de liderazgo, debido a la importancia estratégica de la calidad.

Sin embargo, es de destacar que a partir de la información relevada la calificación de los mandos medios y su grado de profesionalización resulta un factor clave para incorporar como 
rutina el uso del Reporte diseñado. Es decir, los conocimientos y habilidades de los gerentes del Departamento de Servicio (Taller) se identificaron tanto como barreras así como facilitadores, siendo fundamentales para el análisis y discusión de los resultados. Por ejemplo, la concesionaria de mayor tamaño tiene desde el año 2008 sus gerencias comercial y administrativa con personal profesional y capacitado para el puesto de trabajo, observándose mejoras en la interpretación y uso de la información del sistema integral contable y de los Estados Financieros y de Gestión, complemento necesario del Reporte de Evaluación de Desempeño de la Calidad. Esta condición ya fue resaltada por Facin Lavarda et al. (2009a, 2009b) en sus investigaciones.

\section{REFERENCIAS}

Amat, O. \& Campa, F. (2013). Manual del controller. ACCID Comisión de Contabilidad de Gestión. Barcelona: Ed. Profit.

Araújo Pinzón, P. (2003). Nuevo institucionalismo, teoría de la estructuración y cambio en los sistemas y prácticas de contabilidad de gestión: teorías y métodos de investigación. Revista Española de Financiación y Contabilidad, 32 (118), 693-724.

Asociación Española de Contabilidad y Administración de Empresas (AECA) (1995): Costes de calidad, Asociación Española de Contabilidad y Administración de Empresas, Principios de Contabilidad de Gestión, Documento no 11 Madrid.

Atkinson, A. A., Balakrishnan, R., Booth, P., Cote, J. M., Groot, T., Malmi, T., Roberts, H., Uliana, E., \& Wu, A. (1997). New directions in management accounting research. Journal of Management Accounting Research, 9, 79-109.

Ayuso Moya, A. \& Ripoll Feliú, V. (2005). El estudio de casos como prototipo de la investigación en Contabilidad de Gestión desde una perspectiva cualitativa. Revista Iberoamericana de Contabilidad de gestión, 5, 131-168.

Bogt, H.J. \& Helden, G.J. (2000). Accounting change in Dutch government: exploring the gap between expectations and realizations. Management Accounting Research, 11, 263-279.

Burns, J. \& Scapens, R. W. (2000). Conceptualizing management accounting change: an institutional framework. Management Accounting Research, 11, 3-25.

Climent Serrano, S. (2005a). Clasificación de los costes de calidad en la gestión de la Calidad Total. Partida Doble, 171, 88-97.

Climent Serrano, S. (2005b). ¿Cómo medir y calcular los costes de calidad en la empresa. Partida Doble, 170, 32-47.

Cobb, I.; Helliar, C. \& Innes, J. (1995). Management accounting change in a bank. Management Accounting Research, 6, 155-175.

Covaleski, M.; Dirsmith, M \& Michelman, J. E. (1993). "An institutional theory perspective on the DRG framework case-mix accounting systems and health-care organizations". Accounting, Organizations and Society, 18 (1), 65-80.

DiMaggio, P. \& Powell, W. W. (1983). The iron cage revisited: institutional somorphism and collective rationality in organizational fields. American Sociological Review, 48, 147160. 
Facin Lavarda, C.; Ripoll Feliú V. \& Barrachina Palanca, M. (2009a). La interiorización del Cambio de un Sistema Contable de Gestión en la Pequeña Empresa. Revista Contabilidade \& Finanças, USP, São Paulo, 20 (51), 101-115.

Facin Lavarda, C.; Ripoll Feliú V. \& Barrachina Palanca, M. (2009b). Un análisis institucional de la implicación del proceso de cambio de los SCG en la evolución de la eficiencia de la PYME. Rev. Contabilidade \& Finanças, 20 (49), 126-141.

Facin Lavarda, C., Barrachina Palanca, M., \& Ripoll Feliu, V. (2010). Motivos de Cambio de los Sistemas Contables de Gestión en las Pequeñas Empresas. Contabilidade Vista \& Revista, 21 (4), 89-122.

Guerreiro, R.; Agurto Berdejo, L. M.; Pereira, C. A. \& Beuren, I. M. (2012). Institucionalização e resistência em processos de mudanças de sistemas de controle gerencial: um enfoque institucional. Revista Iberoamericana de Contabilidad de Gestión, $\mathrm{X}(19), 1-22$

Hansen, D. \& Mowen, M. (2007). Administración de Costos. Contabilidad y Control. 5ta.Edición. México: Internacional Thompson Editores SA.

Horngren, C.; Foster, G. \& Datar, S. (2002). Contabilidad de Costos. Un enfoque gerencial. México: Ed. Prentice-Hall Hispanoamericana S.A.

Innes, J. \& Mitchell, F. (1990). 'The process of change in management accounting: some field study evidence'. Management Accounting Research, 1, 3-19.

Ksairi, J. (2006). Administración de la Calidad. En: Giménez, C. M. (coord.) y colaboradores, Decisiones en la Gestión de Costos para crear valor.Cap.9. Buenos Aires: Ed. Errepar.

Martínez Ramos, M (2004). Proceso, antecedentes y consecuencias de la adopción de innovaciones contables: contrastación de un modelo integrador. Cuadernos de Economía y Dirección de Empresas, 21, 5-026.

Martínez Ramos, M. (2005). Sistemas de indicadores y cambio contable. Estudio de un caso. Revista Iberoamericana de Contabilidad de Gestión, III (6), 13-38.

Oliver, C. (1991). Strategics responses to institutional processes. Academy of Management Review, 16 (19), 145-179.

Ostengo, H. C. (2014). La Contabilidad de Gestión. En un enfoque de Control de Gestión y Evaluación del Desempeño, para lograr la Medición Integral de la Gestión. Buenos Aires: Ed. Buyatti.

Oyadomari, J. C. T., de Aguiar, A. B., Chen, Y. T., \& Dultra-de-Lima, R. G. (2013). Inovação de práticas de controle gerencial e fontes de informação. Revista de Contabilidade $e$ Organizações, 7(19), 16-26.

Scapens, R.W. (2006). Understanding management accounting practices: A personal journey. The British Accounting Review, 38 (1), 1-30.

Shank J. \& Govindarajan. (1995) Gerencia estratégica de costos. Colombia. Editorial Norma S.A.

Shields, M.D. \& Young, S.M. (1989). A behavioral model for implementing cost management systems. Journal of Cost Management, 17-27. 
Casarsa, F. A. \& Scoponi, L. M..

Gestión de la calidad: una práctica gerencial para impulsar el cambio contable en pymes de redes comerciales automotrices de Argentina

Sulaiman, S.; Mitchell, F. (2005). Utilising a typology of management accounting change: An empirical analysis. Management Accounting Research, 16 (4), 422-437.

Yin, R.K. (1994). Case Study Research. Sage Publications, Londres. 